\title{
Transforming a School into a Learning Community by Integrating FIRST Framework through a Professional Development Framework
}

\author{
Amal Farhat \\ Correspondence: Amal Farhat, School of Education, Lebanese International University, Lebanon. \\ Received: October 23, 2019 \\ Accepted: December 16, 2019 Online Published: December 17, 2019 \\ doi:10.11114/jets.v8i2.4579 \\ URL: https://doi.org/10.11114/jets.v8i2.4579
}

\begin{abstract}
This study recounts the cyclic process that one private school developed and implemented for the purpose of professional development PD of its staff during an academic year. The process consists of five stages that constitute the framework for PD. The content used to implement the PD framework was a learning framework that focuses on students' active deep learning, FIRST. The implementation of the PD incorporated many tasks such as training, coaching, classroom observations and learning walks, all of which were delegated to teachers as a way to distribute leadership. Other tasks included formative assessment of teachers' skills, reflection on practice, and planning for action. At the end of the year, the impact of the PD was investigated through questionnaires, classroom observations, lesson plans, and interviews with students. It was found that teachers preferred the newly adopted PD framework to preceding professional development programs and reported to have benefited more than they had previously. Classroom observations conducted by external and internal observers indicated that the teachers were integrating the majority of the newly introduced skills in their classroom performances. Finally, students, when interviewed, used much of the terminology that were elicited from the learning framework, FIRST, which constituted the content of the PD framework their teachers had undergone. In addition, they reported to have learned considerably from the newly adopted activities and practices by their teachers and enjoyed the new approaches used in their classrooms.
\end{abstract}

Keywords: professional development, distributed leadership, reflection, formative assessment, feedback, FIRST framework

\section{Introduction}

Professional development of teachers is vital for any improvement of the quality of education (AbdulSamad, 2008). Most often, schools rely on training workshops for the purpose of professional development. However, there is little evidence to support that such learning experiences lead to improved classroom practices, for they are isolated experiences that fail to provide feedback and on-going support. Moreover, they do not contribute to the creation of a professional community of learners (Glazer \& Hannafin, 2006). This is why, in an attempt to improve classroom practices in a private school, the school adopted a framework for learning/teaching, delivered it to its teachers within a PD framework that not only incorporated teacher training, but also on-going support through coaching, collaboration, feedback and other clinical practices.

The basic principles of the PD framework are:

- Identifying a limited number of professional development goals per year to work on

- Involving as many of the school staff rather than hiring external trainers

- Using external training and other exposure to professional development outside the school to its utmost in the school by sharing it among teachers and administrators

- Assessing performance and learning outcomes formatively and summatively

- Engaging all teachers, administrators and students in providing feedback on practices

- Assessing practices and their impact on teachers and students

- Planning for action throughout the PD and at the end of the schoolyear

\section{Purpose of the Study}

The study investigated the impact of implementing a PD framework on the teachers, coaches and students in a $\mathrm{k}-9$ 
private school in Bekaa, Lebanon. It implemented a learning framework through a PD framework that incorporated distributing leadership amongst teachers. Formative assessment, reflection, planning for action were among the cyclic practices that characterized the implementation of the program.

\section{Importance of the Study}

Much of the professional development that takes place in schools is in the form of workshops that are attended by a few teachers, while the rest of the school staff, including other teachers, subject coordinators and administrators, know little about it. This leaves it up to the teachers who underwent the training to decide if they want to implement their new learnings in their classroom practices. This study constructs a professional development framework that is ongoing throughout an academic year, includes all schoolteachers and leaders, is cyclic, and involves all participants in tasks to ensure maximum implementation of new practices. Further, feedback, reflection and conferencing are among the repeated practices in the framework. While this framework serves as the structure for professional development, the content is another framework for learning, FIRST, which is new in the literature and has no published studies so far focusing on its application.

\section{Review of Literature}

This section starts with the underlying principles of the FIRST Framework that was adopted by the school as the content for the PD framework under investigation. Then, follow the underlying principles and tenets on which the PD framework was based.

\section{FIRST Framework}

In his book, Bahgat (2018) synthesizes various theories to generate the FIRST Framework. He refers extensively to the theories of experience economy, transfer of learning and 6D model, facilitative learning, active learning, deep learning and adult learning, all of which are classified as the primary theoretical influence (Bahgat, Elsafty, Shaarawy, \& Said, 2018). Other theories that resonate in this book are elaboration theory, ARCS model (attention, relevance, confidence and satisfaction), flow theory, cooperative learning theory, game-based learning and experiential learning theory, which are classified as the secondary theoretical influence. Each of these theories was referred to from varied sources; for example, reference to experiential learning was made to Kolb and to Dewey. The same applies to the rest.

The resulting FIRST Framework includes five domains, each consisting of three principles to add up to 15 principles. They are classified as follows:

Table 1. The domains that the acronym FIRST stands for and the three principles that fall under each domain (Bahgat, 2018)

\begin{tabular}{|c|c|c|c|}
\hline \multicolumn{2}{|r|}{ Domain } & \# & Principles \\
\hline \multirow[t]{3}{*}{$\mathbf{F}$} & \multirow{3}{*}{$\begin{array}{l}\text { Focusing on Learner } \\
\text { Behavior }\end{array}$} & 1 & Individualization \\
\hline & & 2 & Probing and assessing \\
\hline & & 3 & Trust the learner \\
\hline \multirow[t]{3}{*}{$\mathbf{I}$} & \multirow{3}{*}{$\begin{array}{l}\text { Interacting with positive } \\
\text { group dynamics }\end{array}$} & 4 & Social event \\
\hline & & 5 & Positive spirit \\
\hline & & 6 & Motivation and attention \\
\hline \multirow[t]{3}{*}{$\mathbf{R}$} & \multirow{3}{*}{$\begin{array}{l}\text { Reviewing } \\
\text { with RAR }\end{array}$} & 7 & Readiness increase \\
\hline & & 8 & Activity facilitation \\
\hline & & 9 & Reviewing actively \\
\hline \multirow[t]{3}{*}{$\mathbf{S}$} & \multirow{3}{*}{$\begin{array}{l}\text { Sequencing } \\
\text { with SEE }\end{array}$} & 10 & Structuring and sequencing \\
\hline & & 11 & Repetition (without boredom) \\
\hline & & 12 & Linking and summarizing \\
\hline \multirow[t]{3}{*}{$\mathbf{T}$} & \multirow{3}{*}{$\begin{array}{l}\text { Transforming learning } \\
\text { into performance }\end{array}$} & 13 & Reflection on reality \\
\hline & & 14 & Practicing and experiencing \\
\hline & & 15 & Continuity and follow up \\
\hline
\end{tabular}

The five-domain framework, FIRST, aims at immersing the learner in a learning experience that is active and deep. The first domain of the framework, the F, stands for 'focusing on the individual' for "he or she brings in a unique 
background, life experiences, situations, and personal aspirations" to the learning journey (p. II). The second domain, the I, emphasizes group interactions; if they are positive and productive, they can facilitate optimal learning experiences. Reviewing and reflecting are the components of the following domain, the R, which instructs that learning should not head on from one topic to another without giving ample time for learners to reflect on their learning in order to transform their experiences into meaningful ones. Sequencing is what the $\mathrm{S}$ in the fourth domain stands for. It requires that skills and knowledge graduate in difficulty in a logical manner. In addition, this domain involves that the material be paced appropriately and be varied to maintain the interest and active engagement of the learner. Finally is the $\mathrm{T}$ domain, which emphasizes that learning is transferred to the learners' life and work. Once this transfer takes place, the learner acquires new attitudes, skills and knowledge (Bahgat, 2018).

\section{Theories and Tenets Underlying the PD Framework}

The framework for professional development was based on the conception that most of the tenets that apply to student learning can apply to teacher learning as well. Therefore, the PD framework and the FIRST framework often intersect and overlap.

\section{Experiential learning and the practice cycle}

People learn by transforming concrete experiences into knowledge or abstract conceptualization according to Kolb's model of learning. Reflective observation and active experimentation underlie this transformation (Kolb \& Kolb, 2005). These compose the four stages of the adult learning cycle, which provides a model of how supervisors can work with teachers (Randall \& Thornton, 2005). The four stages go parallel to Randall and Thornton's practice cycle (Figure 1) where the concrete experience in the learning cycle is the lesson delivery in the practice cycle. In each of these stages, observation takes place to collect evidence that is necessary in the feedback session. The reflective observation and abstract conceptualization are the second and third phases in the learning cycle and are translated in the practice cycle as the post lesson feedback and debriefing sessions. Here, the teacher is guided to reflect on the process using the evidence collected and is encouraged to discuss the deep structures of the teaching. The final stage is the active experimentation in Kolb's learning cycle paralleled by the lesson stage in Randall and Thornton's practice cycle. In these stages, principles are derived from the lesson, and decisions on how to make use of these principles are made (Randall \& Thornton, 2005).

\section{Kolb's Experiential \\ Learning Cycle}

\section{Advisor's Pedagogic Functions}

Observation to bring evidence to the feedback session on:

Concrete Experience

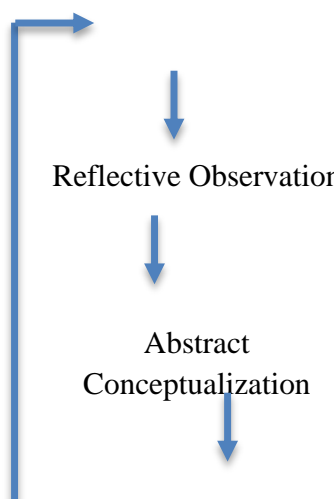

Active Experimentation
The Lesson

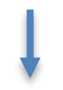

Post Lesson Feedback Session/Debriefing<smiles>[CH]1C=C1</smiles>

The Lesson
1. the way that the teacher has met the pre-agreed on targets of the lesson

2. aspects of the lesson which exemplify new areas of technique/understanding which need to be addressed

Encouraging discussion on the deep structures of teaching to:

1. establish theoretical principles which undergo the observed behaviors

2. relate observed lesson to 'received' knowledge about teaching/learning

3. develop the teacher's personal theoretical models and underlying structures of thought about classrooms and learning
Discuss the use of the principles derived from the lesson to decide:

1. how such principles may be applied to another situation

2. what targets are to be set for the next lesson

3. what evidence the teacher would like the advisor to bring from the next lesson

Figure 1. Comparing the experiential learning stages of Kolb and Randall \& Thornton

The underlying concepts and the practices for experiential learning and the practice cycle are evident in many other 
models such as Korthagen's ALACT model (action, looking back on the action, awareness of essential aspects, creating alternative methods of action and trial), Cogan's eight-stage clinical supervision, and Wallace's six-phase HORACE pattern (Hear, observe, record, analyze, consider, evaluate) (Farhat, 2011).

\section{Collaboration and interaction}

The power of collaboration in the school setting lies in that it allows individuals to pool their resources to achieve a common goal through communication, trust, flexibility, responsiveness to change and a supportive atmosphere (Mackenzie, Zakrzewski, Walker, \& McCluskey, 2008). Collaboration allows teachers to consider themselves as leaders, for while collaborating, they are participating in leadership (Lambert, 2003). This empowers teachers because it provides them with the opportunity to increase their knowledge of teaching and to be active participants in shaping the school culture (Glazer \& Hannafin, 2006).

Michael Fullan has drawn his understanding about how to achieve substantial change in education from his education reform in England and Canada and in major initiatives around the world (Fullan, 2008). Further, he cites many stories of leadership from major companies around the world such as Toyota. Fullan adds a dimension to collaboration, which is peer interaction. To him peer interaction should be positive and purposeful to attain optimal results. Further, three conditions must exist for interaction to be effective: "the larger values of the organization and groups mesh,... information and knowledge about effective practices are widely and openly shared, and ...monitoring mechanisms are in place to detect and address ineffective actions while identifying and consolidating effective practices" (Fullan, 2008, p. 45).

\section{Peer coaching and peer mentoring}

Coaching is a "reform type of professional development" (Seferoglu, 2010) that is job-embedded, ongoing, and directly related to the challenges teachers face daily in their classrooms (Deussen, Robinson, \& Autio, 2007). When coaching is done by peers, teachers are given ownership of the professional development process (Marshal, 2005). Not only that, Marshal adds that peer supervision diminishes bureaucracy from supervision since it allows teachers to work in teams, develop their own plans, share ideas, have face to face feedback, and analyze results. Such practices allow teachers to have more choice, to reflect, to network, to break down the silence that teachers live, and to generate their own solutions, all of which are vital to improve practices in education (Potgieter, 2019).

"A variation of peer coaching is peer mentoring where an experienced teacher and a less experienced one form a relationship" (Farhat, 2017, p. 57). While "coaching is about facilitating someone else's thinking and helping them learn on the job" to promote learning, mentoring is about advising based on personal experience. In a mentoring relationship, the teacher is the owner of the goals and the process, while during coaching, the coach owns the process, and the teacher owns the goal (Miller, 2018). Nonetheless, both practices are low cost and are proven conducive to professional development of teachers (Farhat, 2017).

\section{Professional learning communities}

The concept of professional learning communities has been evolving since 1989 starting with Rosenholtz. Since then several models have emerged to depict what a professional learning community is (Hassan, Ahmad, \& Boon, 2018). Whatever model is considered, the professional learning community is a practice that enhances teacher collaboration and reflection which gradually facilitates the creation of a common vision and norms among teachers. All this is for the optimal goal which is student learning (Avalos, 2011). Improved student outcome is observed "in terms of achievement, social skills, emotional aspects, independence and creativity" as a study by Owen revealed through "achievement data, student work samples, teacher observation and self-reports" (Owen, 2015, p. 57).

For the school to be a professional learning community, administrators, teachers and students must be involved in responsibility and its underlying actions (Sergiovanni \& Starratt, 2006). Further, the community and parents can take part in this community by providing their ideas and feedback. In this way, the school vision is embraced by all (Hassan, Ahmad \& Boon, 2018).

\section{Conferencing}

Conferencing can occur between the coach or mentor and the teacher; both parties are concerned with professional development. It comprises reflection on practice, feedback and planning for future improvement.

\section{Reflection}

Reflection is a major practice in experiential learning. It takes place during conferencing between the coach and the teacher and requires the teachers to delve deeply into their practice and be conscious of their actions. If done properly, reflection becomes the basis for action and thus, professional growth takes place. This requires teachers to reflect on the meaning of their practices to acquire an understanding of the underlying processes rather than jumping to solutions, 
which hardly ever yields any positive outcome (Korthagen, 2014). For this to occur, awareness of essential aspects has to be given special attention. Here comes the role of the coach or mentor to help teachers know what to reflect on (Korthagen, 2014).

\section{Feedback}

Feedback is the dialogue that prevails in a relationship between an agent (being the administrator, supervisor, colleague, coach, mentor, parents, or students) and the teacher. This dialogue or conferencing should lead to discoveries to improve teaching. For this purpose, feedback must be "descriptive, specific and contains information for improvement", and it should match the purpose for which it is given (Bookhart \& Nitko, 2015). The feedback session is critical in the coach-teacher relationship in providing support for the teacher, for it might determine the success of the advisory process (Bookhart \& Nitko, 2015). Feedback is integral in experiential learning and fits in any of its models such as Kolb's experiential cycle, Wallace's Horace pattern or Korthagen's ALACT model.

\section{Professional Development Plans}

A conference in which the coach provides feedback to the teacher and helps the teacher reflect on practice is most beneficial if it results in an outcome (Glickman, Gordon, \& Ross-Gordon, 2017). This outcome is the plan that is based on past teaching practices, emerges from reflection and feedback on performance, and includes goals and purposes for the coming classroom practice. Such a plan is a form of professional development that emerges from actual practices, and thus it is ongoing, connected to practice, aligned with the student learning needs, and focuses on the academic content. Being so makes it more likely to succeed (Loucks-Horsley, Stiles, Mundary, Love, \& Hewson, 2010; Craft, 2004). Further, when done appropriately, it is designed in collaboration between the teacher and the coach. Such collaboration allows for building of strong working relationships, another factor that contributes to the success of professional development (Loucks-Horsley, Stiles, Mundary, Love, \& Hewson, 2010). The plan becomes a contract with defined goals to achieve. Put in an experiential learning cycle, the plan comes at the end of one cycle and feeds into a new one, and thus it will undergo reflection and feedback.

\section{Assessment}

Assessment, in the general sense, is the act of gathering information for decisions about different aspects of the school to improve teaching. To make decisions, different kinds of information are gathered (Bookhart \& Nitko, 2015). In professional development, assessment helps to "collect evidence of the extent to which a program aims have been met," (Loucks-Horsley, Stiles, Mundary, Love, \& Hewson, 2010, p. 45).

\section{Formative Assessment}

"The main purpose of formative assessment is to support learning ... improving on strengths as well as remediating weaknesses," (Bookhart \& Nitko, 2015, p. 141). If not conceived as an act of improving performance, assessment can become stressful with counterproductive results (Acheson \& Gall, 2011). When conceptualizing assessment as a formative process, it becomes a series of growth-oriented tasks that (Robbins \& Alvy, 2014) are less stressful on the teachers and supposedly favored by them. Formative assessment requires gathering information, which is usually done during classroom observations, learning walks, self-assessment, and portfolio compilations. Each practice has its own protocol and tools, and it can be done by a coach, mentor, peer, administrator, external observer, or the teachers themselves. This depends on the purpose of information collection or the kind of information being sought. In either of the cases, the criteria for assessment should be disclosed to the teacher early on (Sergiovanni \& Starratt, 2006). Further, when the teachers are provided room to examine their own and each other's practices and reflect on them, assessment becomes a powerful tool to move teachers closer toward autonomy (Robbins \& Alvy, 2014).

\section{Summative Assessment}

This is usually conducted toward the end of the program to evaluate whether a certain teacher has met the desired outcomes. Most often, this assessment is an administrative act and is often conducted to decide on the continuity of a staff member in the school or not (Sergiovanni \& Starratt, 2006).

\section{Method}

Although this study is limited to one case, a private school, it included its entire staff. The study extended over a period of a whole schoolyear, which allowed for data collection in the actual context of teaching. Further, it made in-depth investigation of the practices, which are of concern in this study, possible. To add to the objectivity of the results and to allow for triangulation, data was collected from several sources: teachers, coaches and students. Interviews, questionnaires and reflection sessions were used for data collection. As with case studies, the aim is not to generalize results. However, with further research and more extended data, generalizations can be constructed for a wider context. 


\section{Participants and context}

The participants in this study were the teaching and leadership staff in a small private school in Bekaa governate in Lebanon. The sample included 25 teachers, five of whom have coordination tasks in addition to their teaching schedule, three administrative personnel; the school principal and two vice-principals, and the educational supervisor. The number of participants adds to 28, six are males and 22 are females. The school has 310 students, and the languages of instruction are Arabic as a native language, English as a first foreign language, and Turkish as a second foreign language.

\section{Procedure/Implementation of one of the PD modules, the FIRST Framework}

To implement FIRST Framework as the training module content for the academic year of 2018-2019, a leadership framework was constructed and adopted. This framework had been initiated in the previous years with other training modules. All throughout, it has undergone much modification and refinement. In its present version, it is composed of five phases: introduce, apply, assess, reflect, plan for action and link and summarize. Because the implementation included all schoolteachers and administrators, and because it was a yearlong process, there were many tasks to be carried out; and to give all participants ownership of the program, tasks had to be distributed.

\section{Delegation of Tasks Among Participants}

Teachers who were delegated coaching tasks are the ones who display high independence and are self-driven, coupled with competence in the required skills and knowledge. This was revealed by formative and summative assessments and previous knowledge and performance of the teacher. Teachers' willingness to carry on tasks were also important in this regard.

The following delegation matrix (RITE International Inc., 2018) is a good visual representation of who can be delegated coaching tasks. Teachers who can be placed as high on both axis: the "skills, experience, knowledge" and the "independent, self-driven" are the most promising candidates.

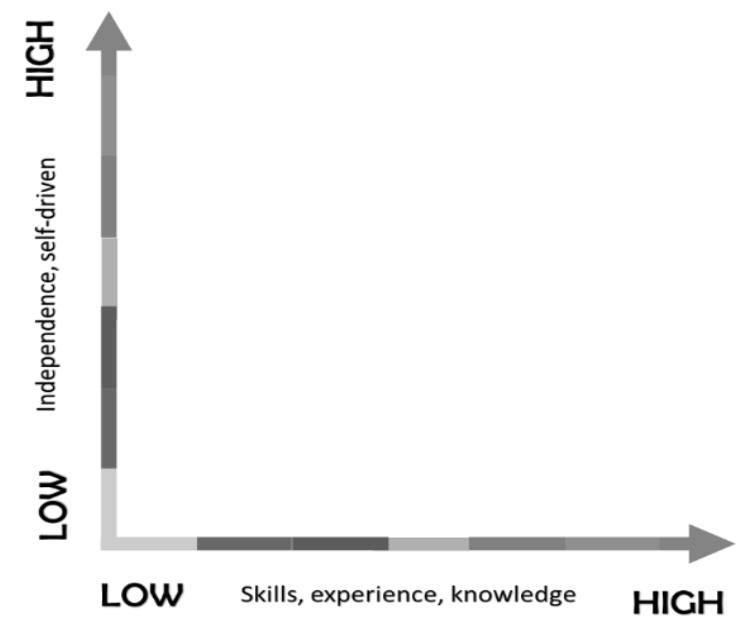

Figure 2. Delegation Matrix - EDULEAD - NAMA Foundation - Coach Manual

Teachers involved, each had one or more of these roles: Trainer, lead coach, coach, mentor, and coachee (teacher). In addition, there was the educational supervisor who outlined the process and facilitation of the process of professional development.

\section{Educational supervisor}

The educational supervisor acted as the PD program leader. She facilitated the running of the PD program; assigned and planned tasks and was the focal reference. In addition, she monitored and ensured implementation and formative and summative evaluations.

\section{Trainers}

The cascade approach was adopted as a strategy to link off-site and school-based training (Craft, 2004). Two key people from the school were trained at an off-site course and were in charge of replicating the training for colleagues back in the school. They were two English language coordinators who received intensive training in Malaysia on FIRST Framework, its principles, classroom applications and facilitation. To ensure the success of the cascading, meetings were held at the school between the educational supervisor and the trainers to discuss how to disseminate the new skills 
and material to teachers and administrators. In these meetings, the school needs were analyzed so that the PD would target them working around the school calendar in a way that the academic year flow would not be disturbed, and implementation and assessment of practices would be possible.

\section{Lead coaches}

There were times when a coach was assigned to lead a group of coaches while implementing the PD modules. Their readiness level promoted them to lead actions, which included: meetings with the coaches, training, delegating tasks, and having other coaches report to them. In these instances, the lead coaches reported periodically to the educational supervisor (figure 3). In our model, the lead coaches were the two trainers who facilitated the training sessions, for they had the most expertise of the content, and thus, were the ideal references for other coaches and teachers during the implementation.

Coaches (teachers)

Those were teachers who met the two criteria: high skills, experience and knowledge; and high independence and self-driving ability (figure 2). They were assigned leadership roles in the PD program and thus had to assist their group members reach their goals and keep them on task.

\section{Emerging mentors}

Whenever there was a teacher who displayed need for additional practice of skills or support, there were always emerging leaders who would act as mentors to their peers. In addition, these mentors can serve later to support new teachers and substitute teachers.

\section{Coachees}

The coachees are the rest of the teachers who underwent the PD and implemented the new learnings, FIRST framework. It is important to note that coaches, mentors and trainers were also implementing FIRST in their practices and were being peer-assessed.

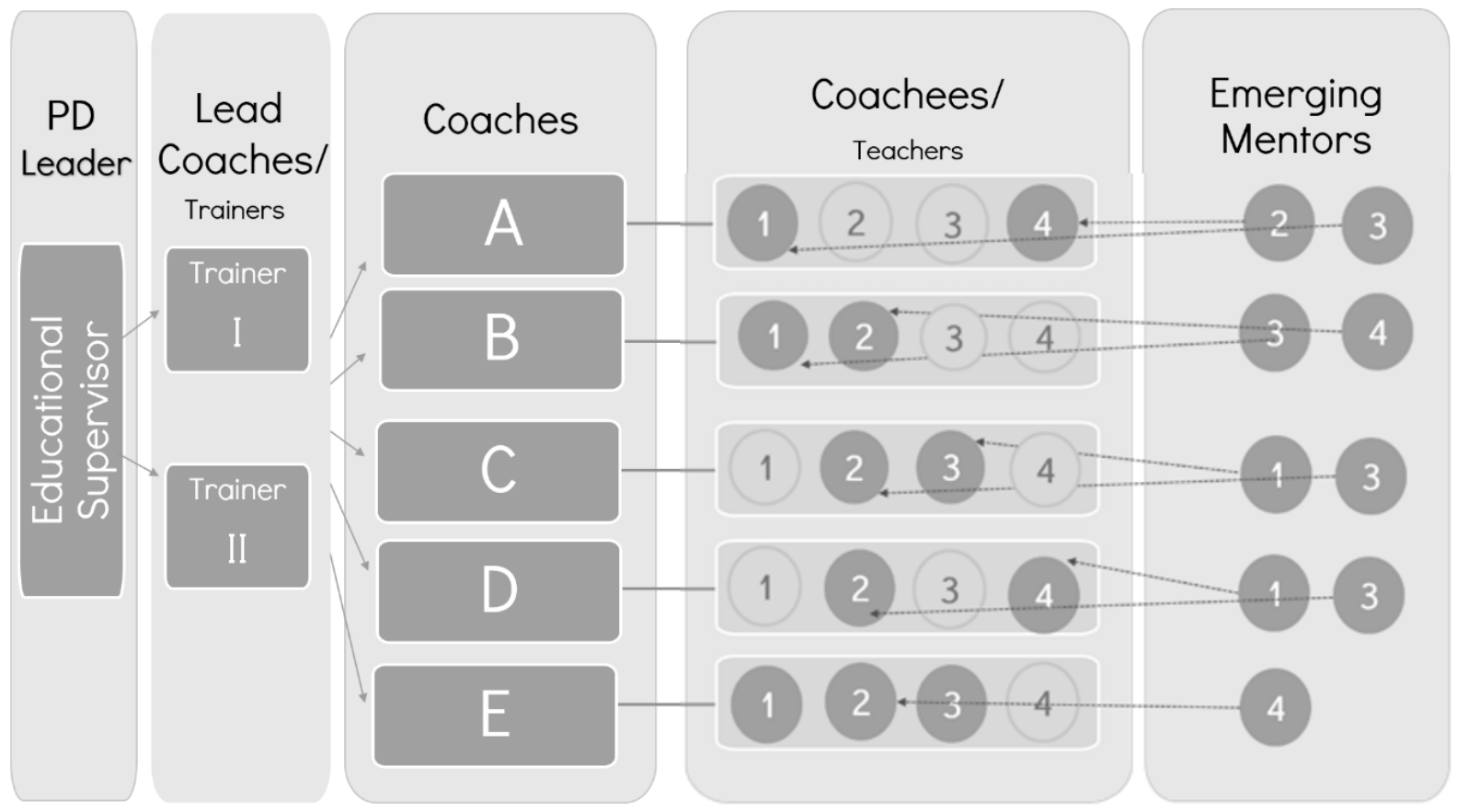

Figure 3. Delegation of leadership tasks. The trainers acted as 'lead coaches' when necessary, and the coachees were the teachers. All participants were engaged in the implementation of the new practices in their classrooms

\section{Implementation cycles-Five-stage PD framework}

The tasks and practices during this period were conducted in a cyclic manner where each cycle was oriented on one of the domains of the FIRST Framework represented by one letter of the word FIRST. Thus, the implementation included five spiral cycles; each building on the previous one, adding new principles and practices. The implementation began in September, at the beginning of the school year and ended in mid-April, toward the end of the year. Each cycle consisted of five interrelated stages: introducing the domain, its principles and activities, teachers applying the domains in their classroom practices, assessing performance, reflecting on practice and linking past domain to the coming one in the new 
cycle. Each cycle lasted about one month. Dates of the activities for the different phases had to be worked around the fixed dates of major school events such as exam periods and holidays. The five-implementation stages are as follows:

1. Introduce

Each cycle commenced with an 8 am to 2 pm training day. A domain of FIRST was introduced with its three principles. The training was attended by the schoolteachers, coordinators and administrators. The trainers facilitated the activities and practices that would serve the domain in a cooperative learning setting that reflected the skills and knowledge of FIRST.

2. Apply

The two weeks that followed the training were designated for the application of the new skills and principles. Teachers worked on integrating new practices in their classrooms to reflect on the domain they were trained on. They were encouraged to consult with the trainers whenever any difficulty arose or they needed help. They were also encouraged to discuss practices with their group coaches and peers.

3. Assess

Assessment was planned and integrated throughout the PD program. Formative assessment of practice supported learning and application of newly introduced principles. During formative assessment, emphasis was on enhancing strengths and remediating deficits in a collaborative non-threatening atmosphere. The focus was always on the content of the training sessions. Summative assessment was done in the last cycle of implementation of FIRST. The purpose was to record the teachers' demonstration of learning of the whole framework, and certification was based on this final assessment (see figure 4).

\section{Formative assessment}

\section{Self-monitoring/assessment checklists}

Teachers received a checklist of the new structures and activities that were introduced to them during the training, which allowed them to integrate the different principles of the framework they were implementing in their teaching practices. This checklist was growing each time a new domain was introduced to include new practices. Teachers used these checklists to monitor their application of the new activities and the frequency of their application. Space to write their self-assessment was provided.

\section{Observation/Learning walks forms}

Classroom observations are key components for collecting data for formative purposes to improve performance. This data is evidence that can be ideal for the feedback in the post-observation conference session (Guskey, 2014). Observations become successful if they are planned ahead of time with a clear focus. The observer can plan to observe for classroom interaction, grouping patterns, cognitive behaviors, levels of questions, teaching styles, learning environments, frequency of questions (Reed \& Bergemann, 2005). A variation to classroom observation is learning walks.

\section{Internal walkers}

Each learning walk was conducted by the group coach who acted as the lead walker, and one other teacher (or two other teachers if their schedule permitted). A learning walk lasted for 10 minutes and was pre-set with the teacher whose class would be visited. The objective of the learning walk was to observe for the implementation of the new principles of the domain that was introduced in the training session. Thus, for each learning walk, the observation form was modified to include new practices. The focus of the learning walk was always clear to the teacher whose class would be visited. After the learning walk, the observers met to debrief on their observation notes and then met with the teacher for a reflective conversation and feeding back to the teacher.

\section{External walkers}

In the fourth cycle of the implementation, three walkers from two educational institutions were invited to the school. They were oriented on the school PD framework, FIRST Framework and the observation forms. They spent a whole day in the school conducting learning walks along with group coaches. In addition, they met with students from different classes and of different achievement levels. Then they wrote their sum up of their classroom observations and presented it to the PD coaches and administration, highlighting the points of strengths they observed and those they thought required attention. 


\section{Google Forms quizzes}

Quizzes were done to ensure that the participants attained the key terms related to the PD content, the underlying theoretical concepts and names and procedures of activities and structures and their applications to serve the FIRST learning domains and principles.

\section{Portfolio}

Throughout the PD, teachers compiled portfolios to document their application and growth process. The portfolios included self-evaluation checklists, post observation self-reflections, observation reports from coaches and peers, lesson plans that highlighted FIRST implementation, and pictures and activities as evidence of application.

\section{Summative assessment}

Teachers received their certification of the training module after the final evaluation that took place in the final cycle of the PD implementation. In this regard, a full 50-minute classroom observation was done for each teacher. In addition, each teacher prepared a lesson that consolidated most of the principles of the yearlong professional development content, FIRST framework.

\section{Observations}

Whole classroom observations were conducted only in the final PD cycle and were done for summative evaluation. Observation forms were designed to include all the practices that were related to the five domains and their 15 principles on which training had occurred. Each teacher was observed, like in learning walks, by the group coach and another peer. Observations were followed by the observers debriefing on the classroom visit, and although they were done for summative purposes, a feedback session with the teacher was done.

\section{Consolidation Lesson Plan}

Each teacher prepared a comprehensive lesson that integrated as many of the FIRST principles as possible. They shared them on Google Drive, and the group coaches checked them and provided the teachers with detailed comments. The lessons were then checked by the educational supervisor who added her own written feedback in the form of comments on positive performance and provided questions to help the teachers further reflect on their lessons and to understand the principles and the unfolding of the FIRST process. 


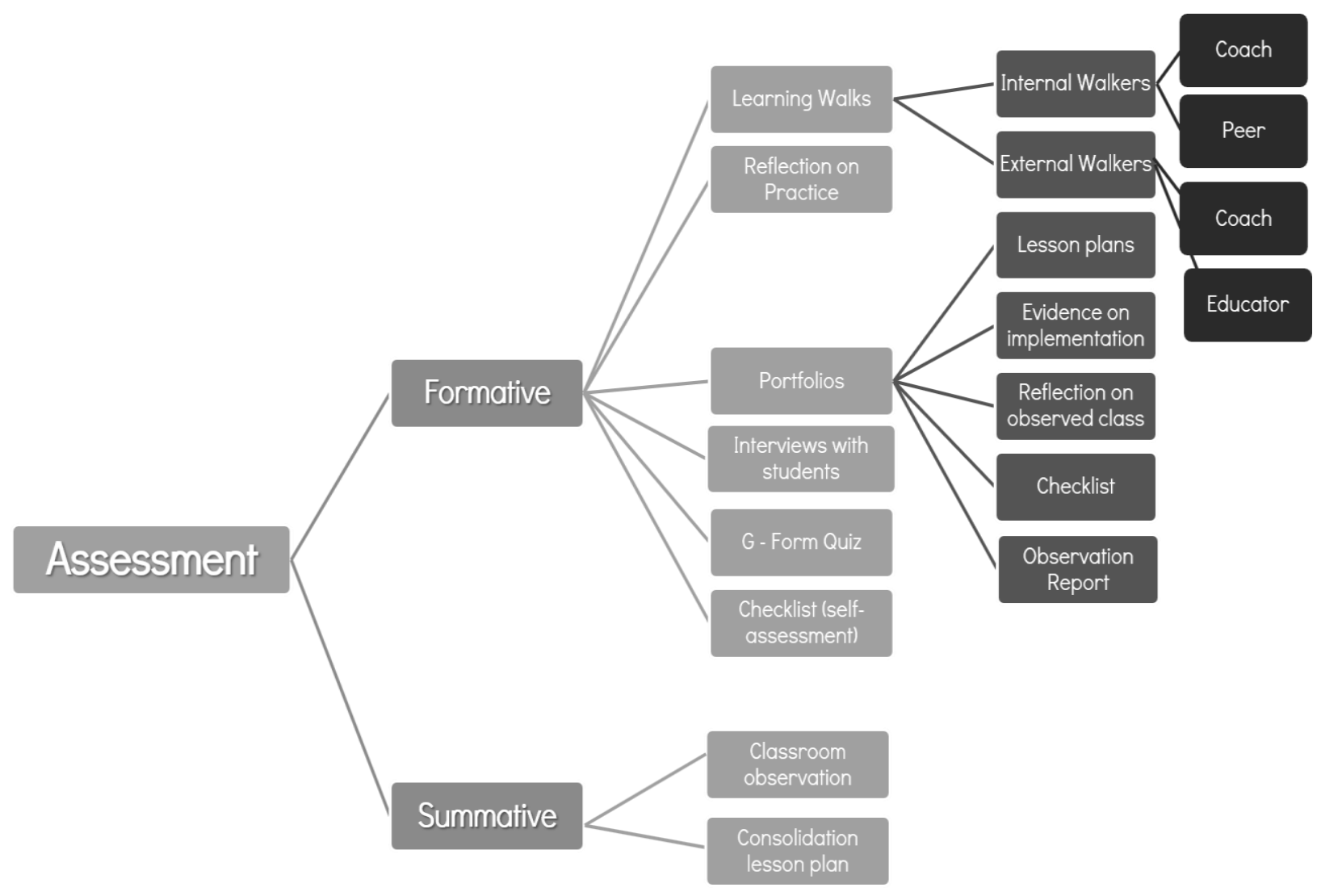

Figure 4. Summary of the different formative and summative assessment tasks during the Assess stage of the PD Framework

4. Reflect: Plan for action

Reflection was an eminent practice throughout the PDP. Two reflection sessions were conducted in each PD cycle:

\section{Reflection session of groups, each headed by its coach}

In this session, the teachers and the coach:

- revisited the objectives of the previous training session/sessions to recall previously taken content.

- reflected on classroom application of new learnings

- made an inventory of what was applied and what was not

- discussed the challenges

- planned for action to be carried out during the time lapse before the following PD cycle began

\section{Reflection session of coaches and the educational supervisor}

In this session, the group coaches met with the educational supervisor and each:

- reported on his/her practices

- reflected on the coaching experience

- reported on what had gone well, what did not and what modifications were done during the coaching period In addition, a plan of action was discussed to overcome difficulties or to modify practices. These action plans fed into new practices to improve performance. 


\section{Link and Summarize ${ }^{1}$}

At the end of each PD cycle and right before the beginning of a new one, collaborative activities were done to review the previously trained on domains, their principles and the structures and activities. This allowed teachers to perceive the content as a smooth continuation that was interrelated and coherent to fit into a holistic framework.

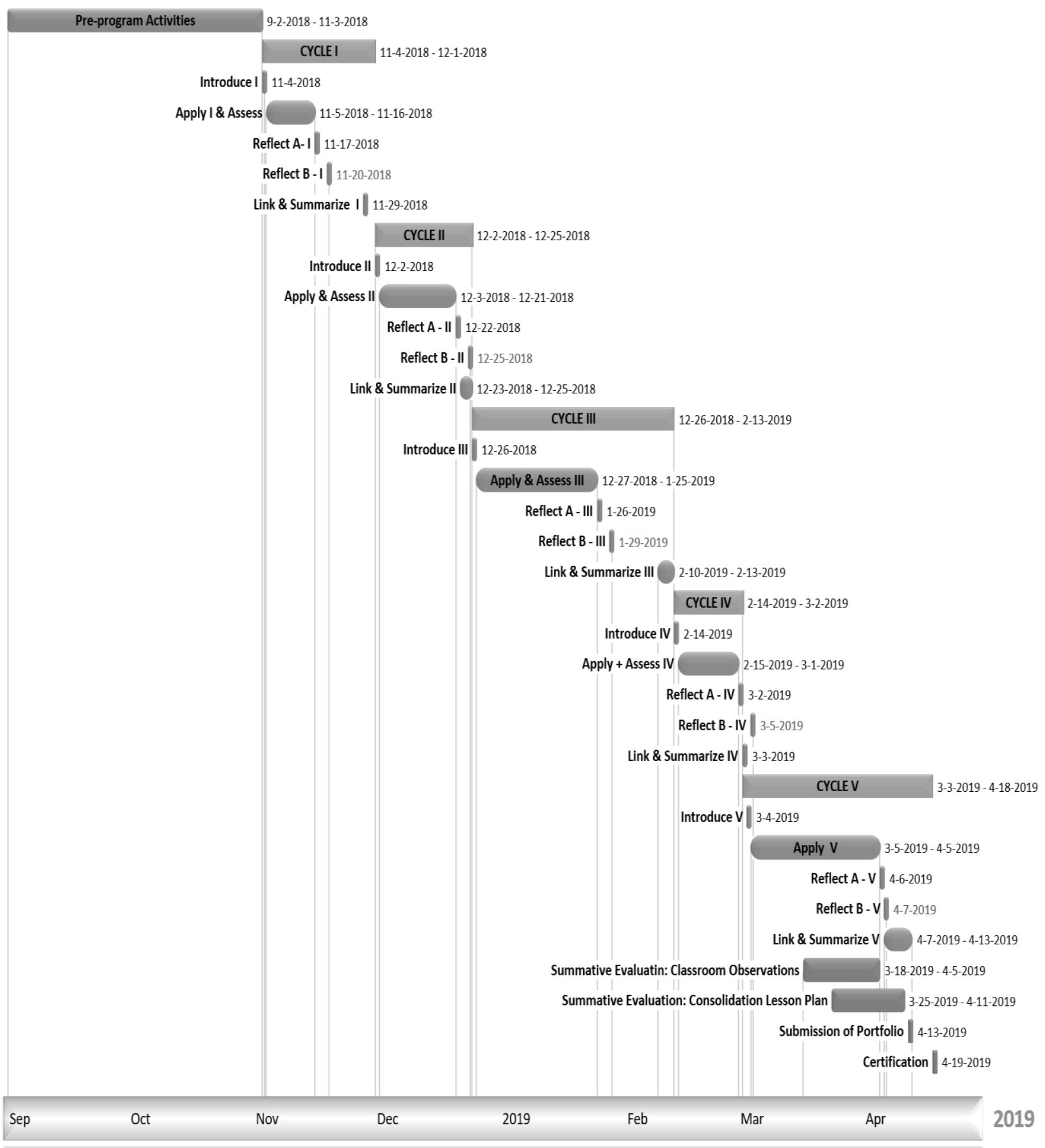

Figure 5. Timeline depicting the major tasks for implementing the five PD cycles throughout the school year, it is clear how assessment and reflection are among the recurrent practices throughout the year

\footnotetext{
"“Linking and summarizing" is used to describe Principle \#12 in the FIRST Framework. In the PD framework, it is borrowed to describe the linking of all the tasks that were done in the preceding PD cycle so that they become a part of a whole before proceeding to the following cycle.
} 


\section{Results}

Indicators of high morale were evident at school during the training modules, and raised spirits and positive attitudes were reported by teachers, students and students' parents. After the training and delegating coaches to follow up on teachers' implementation of their newly acquired skills, teachers' opinions on the new PD framework were elicited through a Google Form questionnaire. Further, opinions on classroom practices were collected during interviews with a random sample of students who were grouped into three groups; each was interviewed by a different educator from outside the school staff.

Teachers not only showed positive perceptions about working within groups and teams, but it was evident to the observer that classrooms were more dynamic and behavior markers of FIRST Framework principles were integrated into teaching after the training sessions and the coach-led group work.

\section{Coaches}

Coaches' perceptions of the program were elicited from the final reflection session that was held at the end of the PD. The major advantages they reported can be summarized as follows:

- The overall morale in the school was positive

- A common language was established among teachers

- The teachers were acquiring automaticity of the newly introduced practices

- Students were more conscious of activity procedures

- There was evidence of implementation of new practices in classroom performance and in daily lesson plans

- Teachers were flexible in applying and modifying their practices to suit their objectives

- Teachers were better-able to suggest new ideas

- Teachers were eager to learn new practices to apply in their classrooms

\section{Teachers}

Teachers' opinions about the PD implementation were elicited through a Google Form questionnaire. Although teachers had undergone several other PD modules in the preceding years, the PD framework suggested in this paper was only applied in full with the FIRST Framework and applied partially with a looser structure with a module on technology in the previous year. When teachers were asked to rank how impactful the implementation of FIRST Framework was on their practices compared to other training modules, FIRST ranked highest. Next to FIRST, was the module on technology (Figure 6). Both training modules were followed by working within groups lead by coaches who continuously supported teachers in their implementation and assisted them to reach their goals through reflection and feedback, however, with the technology module, the PD framework was more loosely structured.

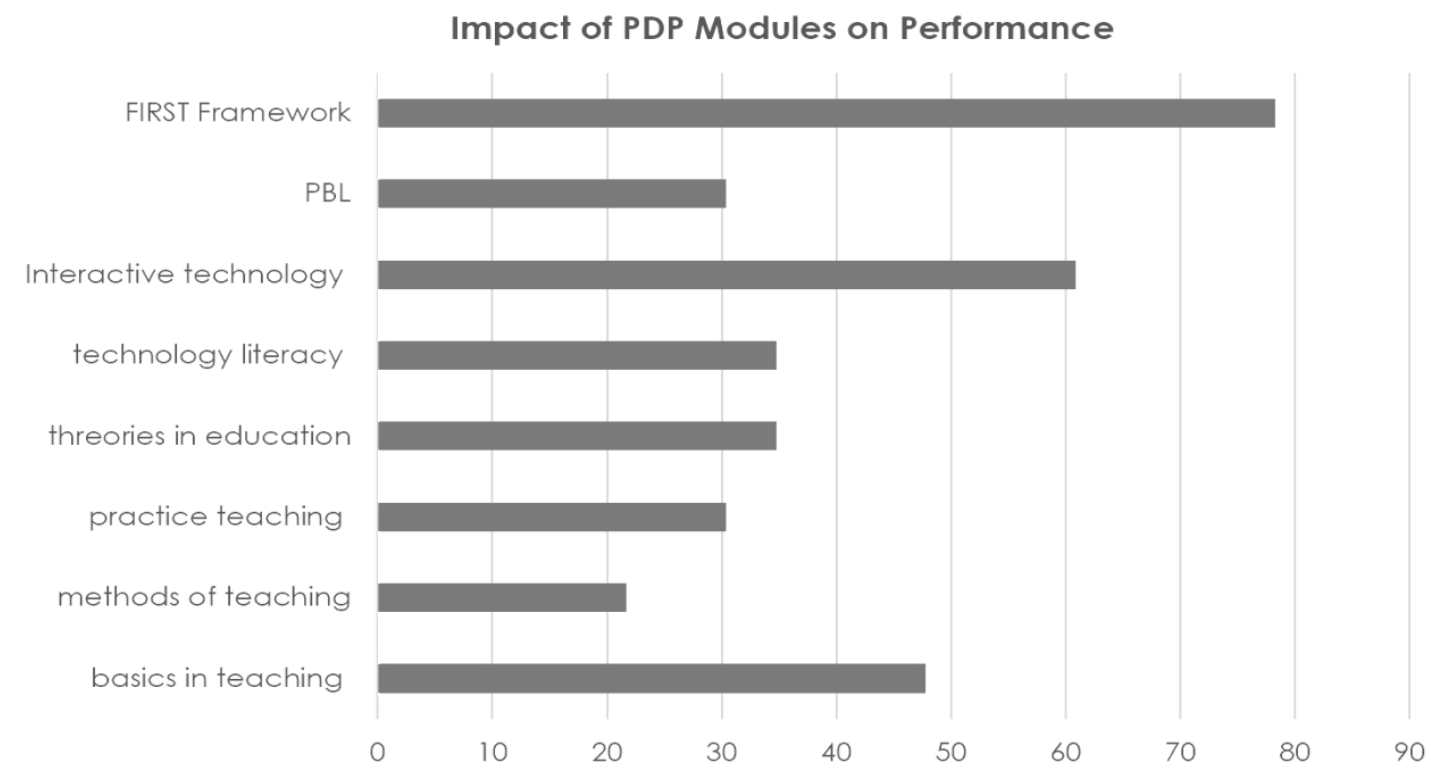

Figure 6. Teachers ordering the PD modules from the most impactful on their classroom performance to the least 
Moreover, teachers reported that workshops that were followed by group work, as the case was when implementing FIRST Framework, were most conducive to their professional growth. It is interesting to notice that workshops followed by peer work are least favorable to teachers.

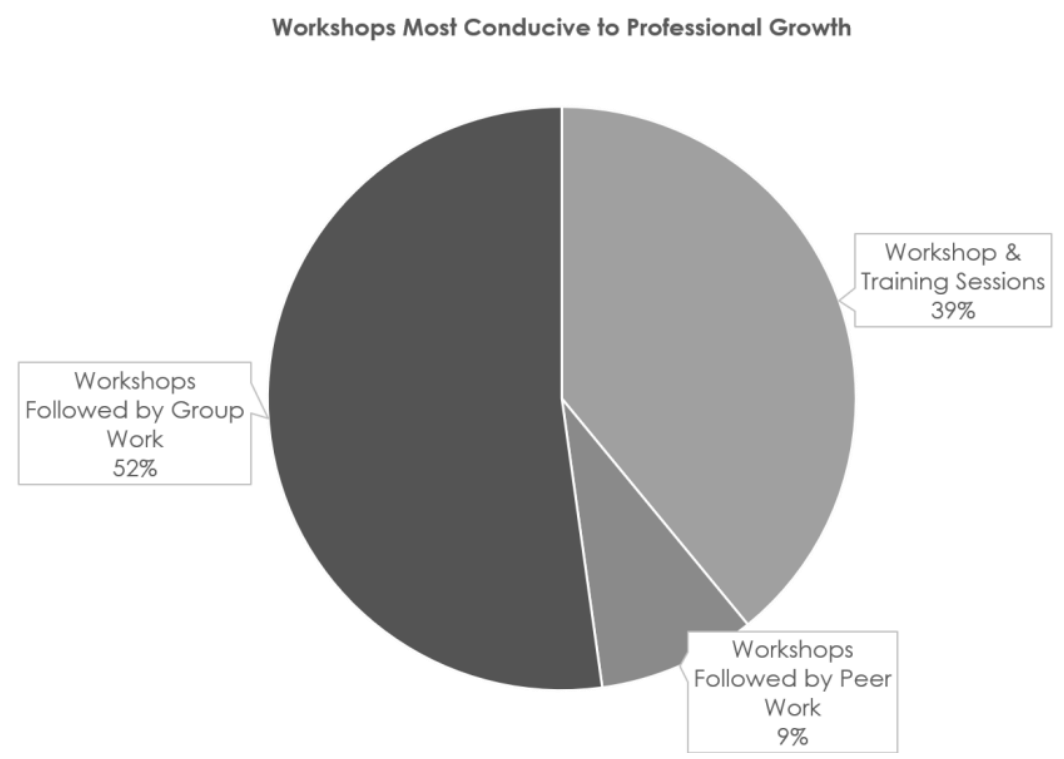

Figure 7. Teachers reporting on the mode of learning they believe is most conducive to their professional growth Teachers have high regard for PD that integrates coaching and its accompanying tasks. None of the teachers reported that such PD is not important. However, all scored the importance either 3, 4 or 5 on a scale from 0 to 5.

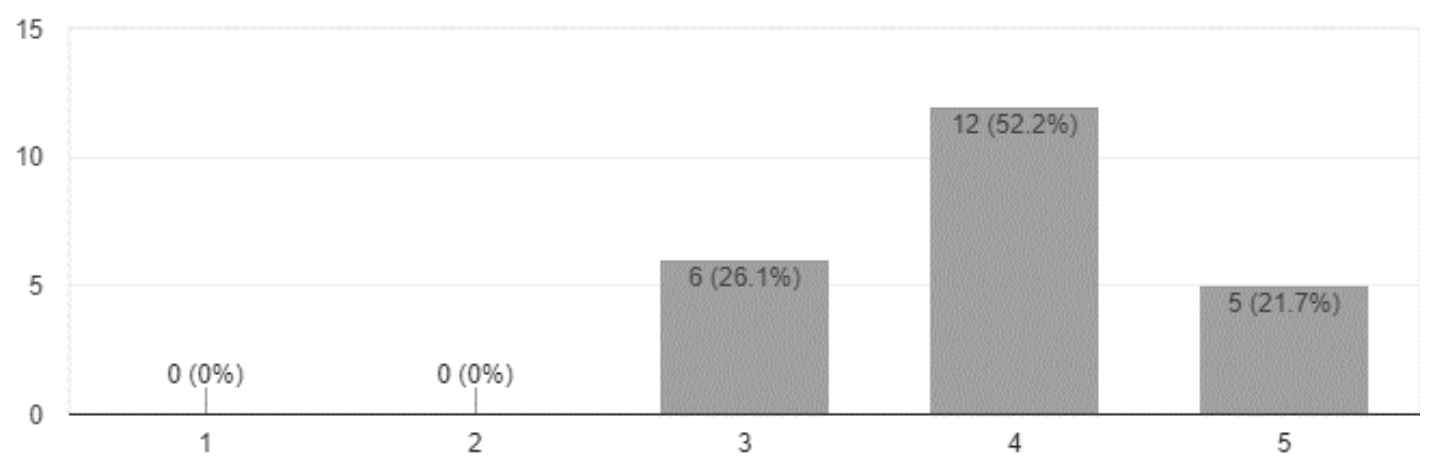

Figure 8. Teachers' evaluation of the importance of following a workshop by coaching varied from $3 / 5$ to $5 / 5$. None of the teachers reported that such training is not effective

\section{Students}

Three groups of students were selected randomly from the different learning cycles: Cycle I, Grades 1 to 3; Cycle II, Grades 4 to 6; and Cycle III, Grades 7 to 9. Questions were prepared by the educational supervisor and reviewed by the trainers and group coaches. These questions were used by external observers (not from the school personnel) and the group coaches in interviews with the groups of students. The questions aimed at having students express their opinions of their classroom dynamics and the existence of practices that reflected the FIRST framework principles. Students' answers included references to the principles. Recurrent words and phrases used by students to describe their classroom activities were "reflection", "linking and summarizing", "energizers", "review", "move on to the next activity", "refer to the rules". Others that show the classroom interaction were "cooperate", "help my friend", "ask for help", "encourage". Students also were able to retrieve names of activities that were new to the classrooms and had been introduced in the training sessions. Some are: "Broken Telephone", "Puzzles", and "Toss the Ball".

\section{Conclusion}

The PD framework in its present form has been continuously modified and refined over the past five years at school. Now it has a clear structure and tasks at every phase. Collaborative work, formative and summative assessments, 
coaching, reflection, feedback, planning for action, reviewing, on-going discussions and networking are among the practices that helped the PD framework succeed. Shifting from a hierarchical structure to one that allows for interaction gives opportunities to skilled and self-driven members to transfer their knowledge and skills to facilitate the creation of a community at school. In this community, each can be a leader in a certain area, and thus leadership is distributed and cascaded among its stakeholders. Although more empirical evidence is required to understand the extent of the success of implementing FIRST Framework and the PD framework adopted by the school, there were clear indicators of their success when they were implemented, one being positive perceptions which is a strong indicator of potential change.

\section{Further Studies}

To provide further empirical evidence on the success of the suggested PD framework and the sustainability of the practices in classroom performance in the following year, a study will be conducted to monitor the implementation of previously trained on practices through classroom observations and studying lesson plans. This allows investigating how sustainable the practices are and whether the one-year PD implementation was sufficient to ensure automaticity of practice; i.e., the teachers implemented the new skills and activities in their teaching without any prompting to do so.

Moreover, it is worthwhile to compare how impactful the implementation of FIRST within the PD framework presented in this paper to other schools that adopted FIRST without the PD framework.

\section{References}

AbdulSamad, Z. (2008). Millennium Development Goals - Report 2008. Paris: United Nations Development Program. Retrieved 7 9, 2019, from https://www.undp.org/content/dam/lebanon/docs/MDG/Publications/MDG_en.pdf

Acheson, K. A., \& Gall, M. D. (2011). Clinical Supervision and Teacher Development: Preservice and Inservice Applications (6 ed.). Hoboken, New Jersey: John Wiley \& Sons.

Avalos, B. (2011). Teacher professional development in teaching and teacher education over ten years. Teaching and Teacher Education (27), 10-20. https://doi.org/10.1016/j.tate.2010.08.007

Bahgat, M. (2018). FIRST Framework - 5 Domains, 15 Principles. SeGa Group LLC.

Bahgat, M., Elsafty, A., Shaarawy, A., \& Said, T. (2018). FIRST Framework Design and Facilitate Active Deep Learner eXperience. Journal of Education and Training Studies, 6(8), 123-138. https://doi.org/10.11114/jets.v6i8.3337

Bookhart, S., \& Nitko, A. (2015). Educational Assessment for Students (7 ed.). Upper Saddle River: Pearson Education.

Craft, A. (2004). Continuing Professional Development: A Practical Guide for Teaches and Schools. London: Routledge. https://doi.org/10.4324/9780203420041

Deussen, C., Robinson, T., \& Autio, E. (2007). Coach can mean many things: five categories of literacy coaches in Reading First. Washington, DC: Department of Education, Institute of Education Sciences, National Center for Education Evaluation and Regional Assistance, Regional Educational Laboratory Northwest. Retrieved 7 9, 2019, from http://ies.ed.gov/ncee/edlabs

Farhat, A. (2011). The Impact of Clinical Supervision on Teachers' Performance in Classroom Managerial Skills. Beirut, Lebanon: Lebanese University.

Farhat, A. (2017). The perceptions of English language teachers and supervisors of supervisory practices. Beirut, Lebanon: Lebanese University.

Fullan, M. (2008). The Six Secrets of Change. San Francisco, California, USA: Jossey-Bass.

Glazer, E., \& Hannafin, M. (2006). The collaborative apprenticeship model: Situated professional development with school settings. Teaching and Teacher Education, 22(2), 179-193. https://doi.org/10.1016/j.tate.2005.09.004

Glickman, C., Gordon, S., \& Ross-Gordon, J. (2017). Supervision and Instructional Leadership (10 ed.). New York, USA: Pearson.

Guskey, R. (2014). Planning Professional Learning. Educational Leadership, 10-16.

Hassan, R., Ahmad, J., \& Boon, Y. (2018). Professional Learning Communities in Malaysia. International Journal of Engineering and Teaching, 7(30), 433-443. https://doi.org/10.14419/ijet.v7i3.30.18347

Kolb, A. Y., \& Kolb, D. A. (2005). Learning Styles and Learning Spaces: Enhancing Experiential Learning in Higher Education. Academy of Management Learning and Education, 4(2), 193-212. https://doi.org/10.5465/amle.2005.17268566

Korthagen, F. (2014). Promoting core reflection in teacher education: Deeping professional growth. In L. Orland-Barak, \& C. Craig, International Teacher Education: Promising Pedagogies (Part A) (pp. 73-89). Bingley, UK: Emerald. 
https://doi.org/10.1108/S1479-368720140000022007

Lambert, L. (2003). Leadership redefined: an evocative context for teacher leadership. School Leadership and Management, 23(4), 421-430. https://doi.org/10.1080/1363243032000150953

Loucks-Horsley, S., Stiles, K. E., Mundary, S., Love, N., \& Hewson, P. W. (2010). Designing Professional Development for Teachers of Science and Mathematics (3 ed.). Thousand Oaks: Corwin.

Mackenzie, L., Zakrzewski, L., Walker, C., \& McCluskey, A. (2008). Meeting the educational needs of fieldwork supervisors: A collaborative workshop developed by New South Wales occupational therapy fieldwork coordinators. Australian Occupational Therapy Journal, 1-10. https://doi.org/10.1111/j.1440-1630.2001.00233.x

Marshal, K. (2005, June). It's time to rethink teacher supervision and evaluation. Phi Delta Kappan, 86(10), 727-735. https://doi.org/10.1177/003172170508601004

Miller, J. (2018). 14 Coaching Principles All Managers Should Practise. Retrieved 7 10, 2019, from Leaderonomics: https://leaderonomics.com/leadership/coaching-principles-managers-should-practise

Owen, S. (2015). Teacher professional learning communities in innovative contexts: 'ah hah moments', 'passion' and 'making a difference' for student learning. Professional Development in Education, 41(1), 57-74. https://doi.org/10.1080/19415257.2013.869504

Potgieter, E. (2019). Transforming Malaysia's Education System. The Bigger Picture. (K. Anissa, Interviewer) Retrieved 7 10, 2019, from https://www.bfm.my/podcast/the-bigger-picture/live-learn/transforming-malaysia-education-system

Randall, M., \& Thornton, B. (2005). Advising and Supporting Teachers. (M. Williams, \& T. Wright, Eds.) Cambridge: Cambridge University Press.

Reed, A., \& Bergemann, V. (2005). A Guide to Observation, Participation, and Reflection in the Classroom. New York: McGraw Hill Higher Education.

RITE International Inc. (2018). 21st Century School Leadership. EDULEAD program. NAMA Foundation.

Robbins, P., \& Alvy, H. B. (2014). The Principal's Companion: Strategies and Hints to Make the Job Easier. Thousand Oaks: Corwin Press.

Seferoglu, S. (2010). Killing two birds with one stone: establishing professional communication among teachers. Procedia Social and Behavioral Science, 574-554. https://doi.org/10.1016/j.sbspro.2010.12.195

Sergiovanni, T., \& Starratt, R. (2006). Supervision: A Redefinition (8 ed.). New York: McGraw Hill.

\section{Copyrights}

Copyright for this article is retained by the author(s), with first publication rights granted to the journal.

This is an open-access article distributed under the terms and conditions of the Creative Commons Attribution license which permits unrestricted use, distribution, and reproduction in any medium, provided the original work is properly cited. 